\title{
CHRONIC ULCERATIVE COLITIS WITH POLYPS
}

\author{
A CONSIDERATion OF the SO-CALled COLItis pOLyposa (VIRChow)*
}

J. H. HEWITT, M.D., AND W. T. HOWARD, M.D. CLEVELAND

The finding of excrescences and polypoid projections of the mucosa in various parts of the alimentary tract is a comparatively frequent occurrence in the post-mortem room. The association of these with inflammation of the intestines, or at least a clinical history of dysentery, while not so frequent, has, nevertheless, been noted and described in the literature for a considerable time.

In 1721 Menzel $^{1}$ described a case in which there was a general inflammation of the intestinal tract and in the colon there were a number of wart-like excrescences. He presents with his report a crude etching of about 7 inches of the colon (Fig. 1). On it there are fifteen polypoid projections. The specimen was removed from a soldier who died of chronic dysentery.

In 1832 Wagner $^{2}$ in his description of the manner of healing of dysenteric ulcers noted that sometimes on the margins of the scars and on the healed surface of the smooth cicatrix of the healed ulcers tiny polypoid excrescences were found.

In 1839 Rokitansky ${ }^{3}$ confirmed this observation of Wagner's and added that these small excrescences had their origin from islands of the mucous membrane that remained after the ulcerative process had ceased. He, moreover, does not limit the size of the projections. Later, ${ }^{4}$ in describing the process of cicatrization of follicular and other ulcers of the colon he described the formation of polypoid growths from the ragged margins of ulcers.

Other systematic writers on pathological anatomy of this period, as Bock $^{5}$ among the German, Habershon, ${ }^{6}$ Wilkes and Moxon ${ }^{7}$ among the

* Submitted for publication Dec. 10, 1914.

* From the Pathological Laboratory of the Cleveland City Hospital and the Western Reserve Medical School.

1. Menzel: Acta Medicorum Berlinensium, 1721, ix, 78.

2. Wagner: Med. Jahrb. d. k. k. ost. Staates, 1832, xi, 274.

3. Rokitansky: Med. Jahrb. d. k. k. ost. Staates, 1939, xxix, 88; also a Manual of Pathological Anatomy, London, 1849, ii, 86.

4. Rokitansky: Lehrbuch der path. Anatomie, Ed. 3, revised, Wien., 1861, iii, 209.

5. Bock: Lehrbuch der path. Anatomie, Ed. 4, Leipsic, 1864, p. 420.

6. Habershon: Diseases of the Abdomen, Ed. 2, London, 1862, p. 384.

7. Wilkes and Moxon: Lectures on Pathological Anatomy, Ed. 2, London, 1875 , p. 416. 
English, copied Rokitansky's descriptions, but added no specific observations.

In 1861 Lebert $^{\mathrm{s}}$ reported the case of a woman, 32 years of age, who lad suffered for years from an obstinate diarrhea. At section the mucous membrane of the colon was found beset with hundreds of little polypi, varying in size from a lentil to a bean, some pedunculated, others sessile. He described these polyps as consisting of fibrous tissue containing ramifying blood-vessels, but no glands. Glandular tubules were, however, to be found surrounding the base of the polyps. These tubules appeared normal.

In the same year Luschka ${ }^{9}$ described a colon containing on its mucosa thousands of polyps. These varied in size from a hemp-seed to a bean and covered the mucosa from the ileo-cecal valve to the anus. On microscopic examination these polyps were found to consist of glands resembling the glands of Lieberkühn, except that they were longer, many of them more or less branched, and some of them dilated

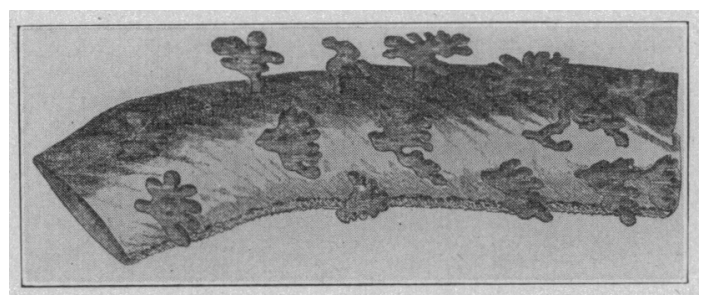

Fig. 1.-A photograph of the etching accompanying Menzel's report. If we compare this with the photograph of the colon from our first case, Figure 3, remembering that the dark areas in both pictures are the ragged tags of mucosa and submucosa, we see that the condition in the two colons must have been practically identical.

into cyst-like spaces. The mucous membrane between the glands was not markedly changed. The patient was a woman 30 years of age She had for years suffered from a bloody diarrhea.

These last two cases, together with Menzel's, Virchow ${ }^{10}$ has given as examples of a condition of the colon which he has called colitis polyposa. To these he has added one case. It was that of a boy 15 years of age who had died of dysentery. The polyps in this case were of the nature of vesicular, fluctuating prominences (Fig. 2). Many of them had scattered over their surfaces small openings from which gelatinous material protruded and could be expressed. Similar material was to be found in the mucosa between the polyps. On microscopic examination these vesicles were found to be dilated crypts of

8. Lebert: Traité d'anatomie path., Paris, 1861, ii, 316.

9. Luschka: Virchow's Arch. f. path. Anat., 1861, xx, 133.

10. Virchow: Die krankhaften Geschwülste, Berlin, 1863, i, 243. 
Lieberkiihn filled with mucous material. To this condition Virchow gave the name colitis polyposa cystica.

In 1881 Woodward, ${ }^{11}$ the author of the "Medical and Surgical History of the War of the Rebellion," described two specimens from a colon that was sent to the Museum of the Surgeon General's Office for preservation. The patient was a woman aged 44, who for seven months before death was afflicted with a severe bloody diarrhea. At autopsy the jleum for 4 inches above the ileocecal valve and the colon for its whole length appeared ulcerated and inflamed. In the lower part of the transverse colon there were to be seen single follicular ulcers. These became larger and more numerous in the upper part of the descending colon, till a point was reached at which the whole nuucosa was occupied by a single ulcer on the base of which there were numerous islands of thickened and puckered, undestroyed mucous

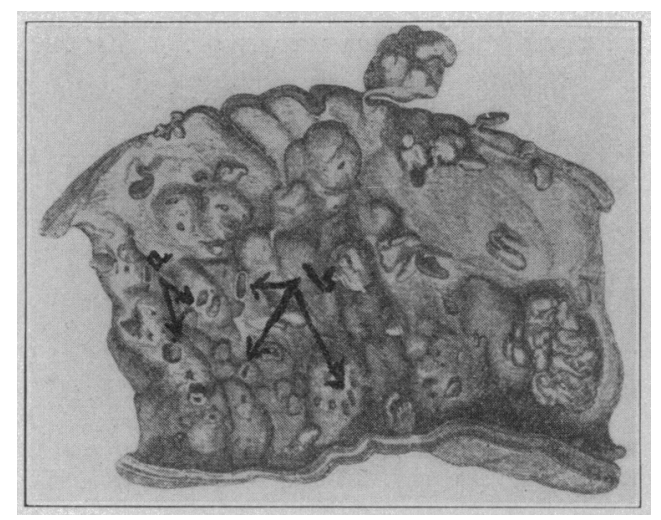

Fig. 2.-A copy of a portion of the colon from Virchow's case of colitis polyposa cystica. At "a" and "b" are to be seen open spaces. This suggests that secretions had accumulated in some of the spaces till they ruptured, which would represent a stage farther in this process than we have described.

membrane. The whole mucous surface of the lower portion of the descending colon was oscupied by a single ulcer, projecting from the base of which were thirteen polypoid excrescences, some measuring as much as $14 \mathrm{~mm}$. in length and $4 \mathrm{~mm}$. in diameter. Some of the projections were more or less branched, but attached by a single pedicle like a genuine polyp; others were attached by double pedicles.

On microscopical examination the polyps were found to be composed of a central mass of connective tissue and a peripheral border of mucous membrane in a condition like that commonly found in chronic inflammation of the colon. The mucous membrane extended over the surface of the excrescence and its pedicle as far as its base, but was

11. Woodward: Am. Jour. Med. Sc., 1881, 1xxxi, new series, p. 142. 
absent from the surrounding flat surface of the intestine between the adjacent polyps. The intervening surface was composed of a vascular granulating tissue containing everywhere a large number of lymphoid cells. The glands of Lieberkiihn over some of the polyps exhibited active hyperplasia.

The first case of this condition that came under our observation was necropsied at the Cleveland City Hospital about ten years ago. The patient was a woman about 36 years of age. About six months before entering the hospital she had given birth to a normal child. For a considerable time before admission she had been afflicted with a more or less severe diarrhea. Three months before admission this diarrhea had become a dysentery of a very annoying and exhausting character. She was in the hospital only a few weeks when death ensued, apparently from inanition and exhaustion.

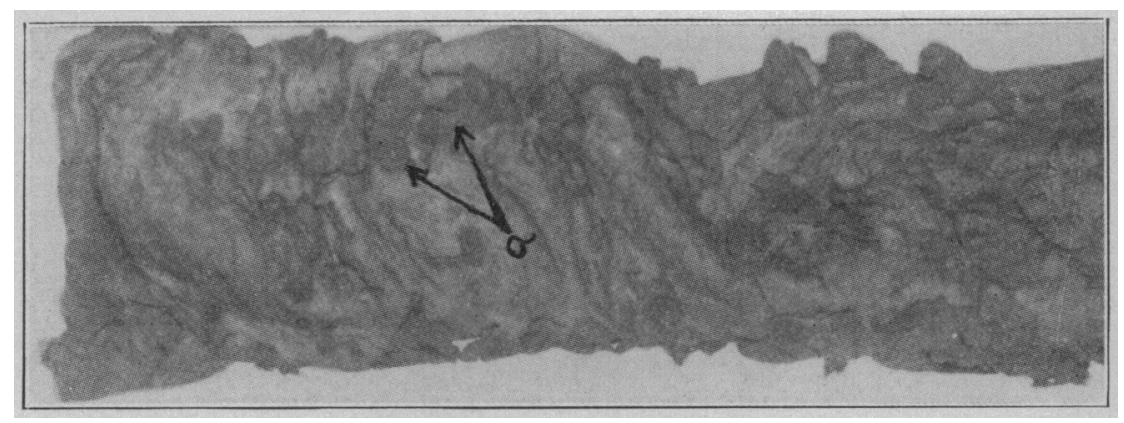

Fig. 3.-A portion of the colon from our first case. The ragged tags of mucosa and submucosa, as seen at "a," are the darker areas. The specimell having been preserved in alcohol had so faded that there was little contrast between the parts.

At the post-mortem examination the only lesion of importance found was in the colon. Here the entire mucous membrane from the ileocecal valve to the rectum was uniformly deeply ulcerated and existed as tags and localized islands (Fig. 3). The wall of the colon was moderately and generally thickened. In microscopic sections it was seen that the ulceration had extended through the submucosa to the muscularis (Fig. 4). The muscularis remained exposed and naked. Near its mucosal surface and extending into it there were numerous islands and columns of lymphocytes and polymorphonuclear leukocytes. There were also scattered eosinophils and plasma cells. The pedicle of the ragged tag of mucosa was composed of swollen and edematous submucosal tissue. In it were a number of blood-vessels, clusters and columns of lymphocytes and polymorphonuclear leukocytes with here and there scattered single eosinophils and plasma cells. The ragged tags were made up of mucosa and a portion of the attached 
submucosa. The submucosal portion was everywhere infiltrated with leukocytes of the same character as those noted in the muscularis and pedicle. Large numbers of leukocytes were also seen in the mucosa between the tubules. The glands of Lieberkühn were everywhere more or less intact and there was no marked increase in the connective tissue between them. In certain places there was deposited between the tubules a brownish substance arranged in cell-like masses and in fine granular droplets. The peritoneum was slightly thickened and infiltrated with small round cells.

The following, our second observation, was more recent:

Patient.-A white man, aged 40, an American, an elevator man by occupation, was admitted to the Cleveland City Hospital July 26, 1913.

History.-His family history and personal history were unimportant. His present illness began with frequent stools two months before admission to the

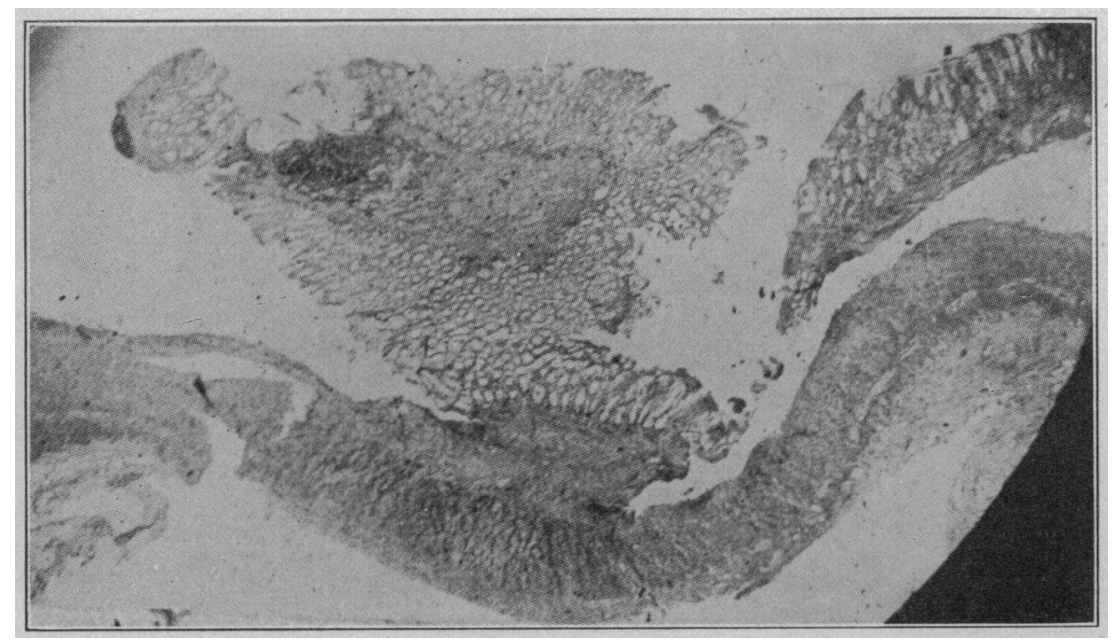

Fig. 4.-A very low-power microscopic view of one of the tags of preserved mucosa and submucosa from our first case. It is to be noted here that there are no cystic spaces and the mucosa that remains is comparatively normal.

hospital. In spite of medical attention these had persisted and had recently been associated with great loss of weight and strength.

Physical Examination.-The patient was a well-developed but poorly nourished man. The skin was anemic, pale, yellow and dry. There were occasional râles to be heard over the chest and a soft systolic murmur along the left border of the sternum. No palpable masses were to be felt over the abdomen. On rectal examination a finger's length up the rectum a hard raised ring could be felt and all around it there were elevated masses. Blood and mucus came away readily with the finger as it was withdrawn. The blood-count on admission was, red blood cells, 4,048,000; white blood-cells, 6,600; hemoglobin, 50 per cent. Differential count, polymorphonuclear neutrophils, 63.5 per cent.; small mononuclears, 18.5 per cent.; large mononuclears, 7 per cent.; transitionals, 5 per cent.; eosinophils, 0.5 per cent.; mast cells, 0.5 per cent. There was fairly marked anisocytosis and poikilocytosis. A specimen of feces 
examined on admission was of a reddish-brown color and of very foul odor. It gave a positive test for bile. Microscopically numerous red blood-cells were to be seen but no amebas parasites, or ova of parasites. The Wassermann reaction was negative. Examination of the urine gave, on admission, a faint trace of albumin. This soon disappeared, and thereafter the urine was negative for albumin, sugar and casts.

Course.-The patient was in the hospital a little over three months and three weeks. During this period the temperature was quite variable but never above 101. Generally it was normal or subnormal. The number of stools varied from one to four per day. The patient died in the hospital.

Clinical Diagnosis.-Carcinoma of rectum.

Necropsy.-Performed about six hours after death. Excepting a moderate parenchymatous degeneration of the heart muscle, liver and kidneys, and a peripheral fatty degeneration of the liver lobules, there were no lesions of importance to be noted outside of the alimentary tract.

The stomach, duodenum and jejunum presented nothing markedly abnormal.

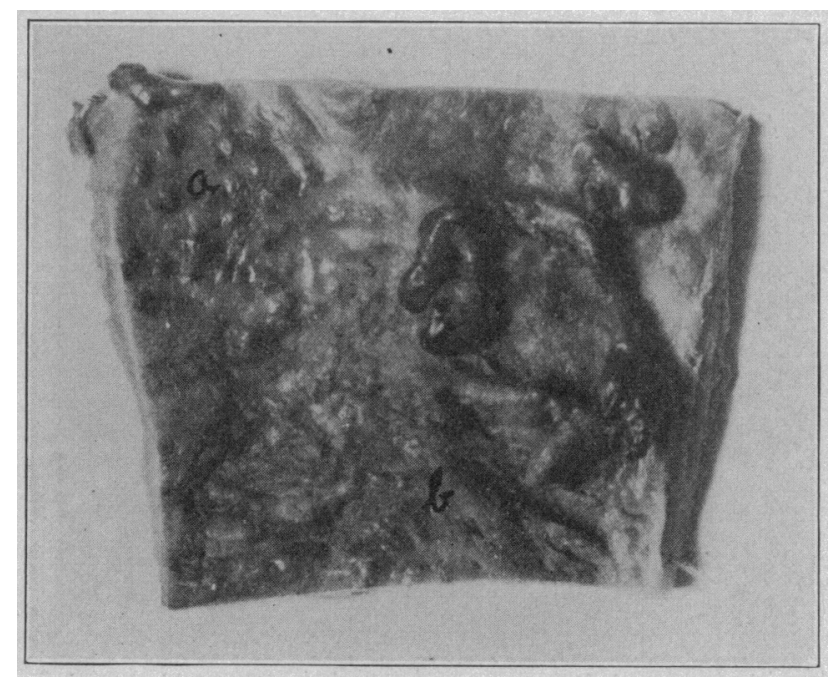

Fig. 5.-A cluster of polyps from our second case. At $a$ and $b$ are to be seen numerous small islands of mucosa and of submucosa.

The mucosa of the lower two-thirds of the ileum was injected, edematous, and its surface covered with a thin, grayish layer of exudate. At irregular intervals small areas of marked injection, as of beginning ulcers, were to be noted. In the lower portion of the ileum, near the ileocecal valve, and in the cecum there were single ulcers. These ulcers were of all sizes from a millimeter to a centimeter in diameter. The small ulcers were of a "punched-out" character and extended only through the mucous membrane. The larger ulcers were very irregular, with ragged margins and floor, and extended deeper into the intestinal wall. On the base of several of the largest ulcers there were attached islands and tags of mucosa and submucosa.

The appendix appeared normal and not to have been at all affected by the inflammatory process involving the cecum and ileum.

The wall of the colon was generally and moderately thickened, rather fibrous and stiffly flexible, though in some places it had been so eroded as to be thinner than normal. The intestine was generally contracted and its lumen narrowed. The mucosa of the ascending and transverse portion was covered 
with a thin layer of grayish exudate. It was moderately injected and, over irregular areas, eroded to varying depths. Over the eroded areas were to be seen islands of deeply injected mucosa. Many of the small tufts of mucosa were attached by slender pedicles of submucosa and were easily removed by passing the finger over the surface. In the descending colon the mucosa was likewise injected and eroded. At a point about $8 \mathrm{~cm}$. above the sigmoid flexure there were to be seen a few short polypous projections. These projections measured from 2 to $3 \mathrm{~mm}$. in diameter. They were stubby and attached by a relatively thick pedicle. About the sigmoid flexures there was a cluster of fairly large and long polypous masses. One of these masses in particular had a long slender pedicle and a clubbed termination. It measured about $2.5 \mathrm{~cm}$. in total length and the clubbed extremity $4 \mathrm{~mm}$. in diameter at its widest part.

From the sigmoid flexure to about $12 \mathrm{~cm}$. above the external sphincter of the anus polypous projections were more numerous and of various sizes and shapes. Some of the polyps were small sessile projections, measuring from 1 to $2 \mathrm{~mm}$. in height and in diameter; others were irregular, 0.5 to $1.5 \mathrm{~cm}$. in length and in diameter, attached by short slender pedicles - some of the

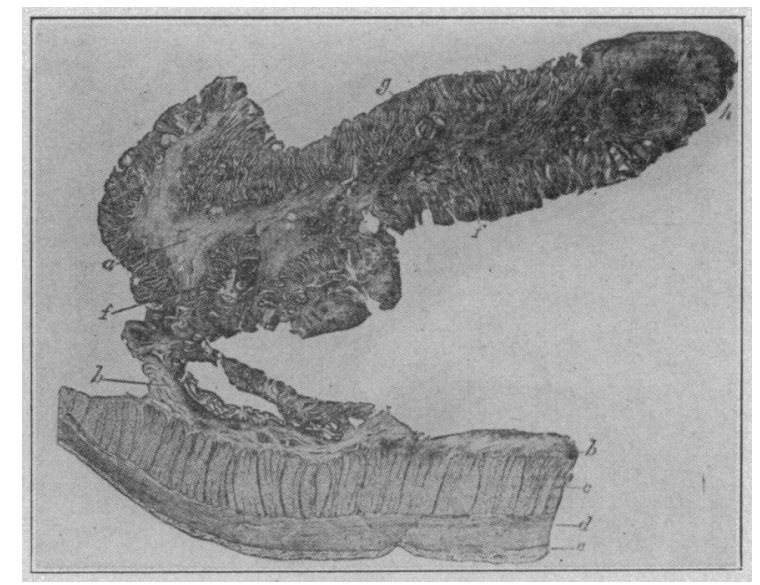

Fig. 6.-A copy of the drawing of a microscopic section of one of the polyps from Woodward's case. The central mass of connective tissue and the surrounding layer of preserved mucosa is well shown.

pedicles appearing so slender as to be scarcely strong enough to support the nodule on their ends (Fig. 5). In all, there were about forty polypous projections.

Microscopic Examination.-In microscopic sections of the lower portion of the ileum the mucous membrane was found to be swollen and edematous. Its surface was covered with a layer of mucus and detritus in which large numbers of leukocytes and glandular desquamated cells were to be seen. The connective tissue between the crypts and glands of Lieberkühn was moderately increased and infiltrated with polymorphonuclear leukocytes, lymphocytes and plasma cells. The blood-vessels were dilated and filled with blood. The submucosa and muscular layer were likewise swollen, edematous and infiltrated with leukocytes. The peritoneal layer was slightly swollen and infiltrated with leukocytes, but there was no exudate on its surface.

In sections of the single ulcers in the lower portion of the ileum and in the cecum there were seen to be areas of necrosis and ulceration, in some places extending no deeper than the mucosa; in other places, however, particularly in association with the larger ulcers, the necrosis extended through the sub- 
mucosa to the muscularis. The margins of the ulcers were swollen, edematous and infiltrated with fibroblasts, large numbers of lymphocytes, polymorphonuclear leukocytes, eosinophils and plasma cells. Some of the margins were sloping and fairly smooth; others were deeply undermined, irregular and ragged. The floor of the ulcers, particularly the large ulcers, was, for the most part, smooth but irregular in outline. There were small elevations on the floor of many of them. These elevations were quite vascular. Some of them were covered with mucous glands; others contained only the fundi of the glands, while others were simple vascular tufts without covering.

The mucous surface of the colon everywhere presented the picture of a chronic inflammatory and ulcerative process with here and there areas and islands of granulation tissue. The surface was covered with a layer of necrosed tissue cells which extended to a variable depth from a few micromillimeters below the surface of the mucosa to several micromillimeters into the submucosa, even to the muscular layer. Beneath the layer of necrotic cells the glandular tubules, where present, were spread far apart by the proliferation of fibroblasts and the infiltration of lymphocytes and polymorphonuclear leukocytes, eosinophils and plasma cells. In most places only the bases of the crypts of Lieberkühn remained. In some places these had been overgrown by the

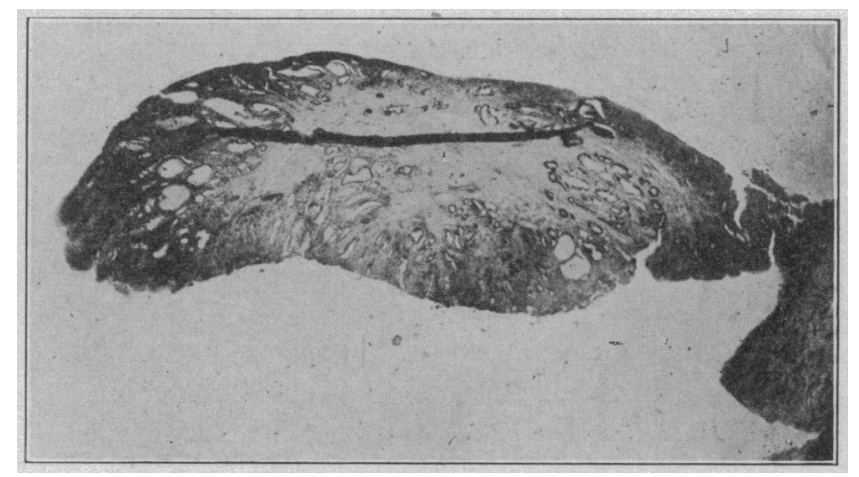

Fig. 7.-A very low power photomicrograph of a section of one of the polyps from our second case to show the dilated cystic spaces in the mucous layer. The dark line across the top represents a fold in the section.

fibroblasts and the accumulation of secretions had caused them to become dilated and to appear as small cysts. The blood-vessels and capillaries were dilated and congested. Scattered areas of hemorrhage were to be seen on the surface. The submucosa, where not eroded, was generally thickened and fibrous. Infiltrating it were a number of scattered areas of leukocytes, eosinophils and plasma cells. The solitary follicles were small and irregular in size and distribution. The muscular layers were moderately infiltrated with lymphocytes, leukocytes, eosinophils and plasma cells. The peritoneum appeared slightly thickened.

The sessile projections and polyps, noted in the descending colon and rectum, microscopically presented the same appearance as that described and pictured by Woodward in the case he described (Fig. 6). There was a central mass of connective tissue which formed the base and support of the polyp. The central connective tissue mass was surrounded by an irregular, rather thick, layer of glandular acini and tubules. The connective tissue extended between the tubules and had in places contracted and occluded them, causing a retention of secretions of the glands and cyst-like dilatations (Fig. 7). The structures were quite vascular and everywhere infiltrated with lymphocytes, polymorphonuclear leukocytes, eosinophils, plasma cells and large epithelioid cells 
The mucosae around the bases and pedicles were for the most part absent, or represented only by scattered fundi of crypts imbedded in fibrous tissue. They were very vascular. The blood-vessels were dilated and engorged with blood. Many of the smaller tufts were made up entirely of collections of budding blood-vessels, fibroblasts, and leukocytes without mucous crypts or glands.

The islands and tags of mucosa and submucosa that had been the source of the polyp formation appeared to depend for their preservation on the blood-vascular arrangement; for it was to be noted that the polyps in the rectum were situated along the side of the intestinal wall, while higher up and in the colon the polyps were situated along the line of attachment of the mesentery, an arrangement that coincides with the blood-supply of the parts. The blood-supply of these small and localized areas appeared to have been sufficient to withstand the destructive action of the inflammatory process, so that necrosis did not take place. The coincident increased blood-supply did, however, produce active hyperplasia of the mucous glands and the submucous connective tissue, with consequent polyp-like formations, as described by Rokitansky. The increased and proliferated fibrous tissue on contracting had caused an occlusion of many of the tubules and retentions of their secretions had caused cyst-like formations, as described by Virchow. Probably, as Virchow has suggested, the formation and lengthening of the pedicles of the polyps had been aided by the active peristalsis and the passing of the feces over the surface of the polyp. Our second specimen, like Luschka's, was not cystic, but cyst-like spaces were present over the mucous surface of the colon between the polyps and over the surfaces of the polyps (Fig. 7).

It appears very probable that the two cases which we have here presented represent, respectively, a very early and a comparatively late stage in this particular condition of the colon designated by Virchow as colitis polyposa. If so, they, with the cases reported in the literature, aid us materially in working out the natural pathological history of the lesions of this affection and of ulcers of the alimentary tract.

There appears in the beginning of this disease to be a general colitis, producing a number of local undermining ulcers similar to those found in our second case in the cecum and in the lower portion of the ileum, near the ileocecal valve. Clinically, there is associated with the lesions at this stage a moderate diarrhea. The ulcers tend to increase in number and in size till nearly the whole mucous surface of the colon is involved. Clinically, during this period there is an increase in the number and a change in the character of the stools. The ulcers as they increase in size fuse and form large irregular ulcerated areas, similar to those presented in our first specimen (Fig. 3). The ulcerative process, though severe and chronic, is of such a character that portions 
of the mucosa and submucosa adjacent to and supplied, apparently, by the primary arterial branches is preserved. These portions of the mucosa and submucosa remain as ragged tags scattered over the surface of the colon. As the process ameliorates and healing begins the irregular margins of these tags become smoothed off and remain as rounded sessile elevations or as polypoid projections of the mucous surface. The portions of the mucosa that remain in these areas regenerate over the surface, around the base or pedicle and, if conditions remain favorable, ultimately, over the barren and denuded submucosa and together with submucosa over the muscular layer. The mucosa may thus be completely restored, and, with its numerous scattered polypous projections, present a perfect picture of colitis polyposa. Coincident with the process of healing, and later, the proliferated fibroblasts begin to contract, as in the cicatrization of a wound. This leads to an occlusion of the orifices of certain of the tubules situated in the polyps and over the mucosa between the polyps. There is then an accumulation of secretions in these occluded tubules with the ultimate formation of retention cysts. These of course increase in size as long as there are secreting cells in their walls, and as there are a greater number of tubules over the surface of the polyp than over the surface of the mucosa, the polyp may appear as a collection of small cysts. It is probably in this manner, as before stated, that the condition which Virchow has designated as colitis polyposa cystica is brought about. It is the end stage of colitis polyposa. 